\title{
A Comparison of the Healing Capabilities of Various Grafting Materials in Critical-Size Defects in Guinea Pig Calvaria
}

\author{
Farin Kiany Yazdi, DMD, MSc ${ }^{1}$ /Ehsan Mostaghni, DMD, $\mathrm{MSc}^{2}$ /Somaye Ansari Moghadam, DMD, MSc ${ }^{3}$ / \\ Sharieh Faghihi, DMD, MSc ${ }^{4} /$ Ahmad Monabati, MD$/$ Reza Amid, DMD, MSc ${ }^{6}$
}

\begin{abstract}
Purpose: To estimate the efficacy of various bone grafting materials in the healing of 8-mm-diameter criticalsize defects (CSD) in guinea pig calvaria. Methods: In this randomized trial study, critical-size defects were created in the calvaria of 36 guinea pigs 6 months of age. Animals were assigned into three groups and each received one of three experimental protocols. In protocol $A$, the right-side defect was filled with macroporous biphasic calcium phosphate (MBCP Gel) and the left side was left empty as a control. In protocol B, the rightside defect was filled with demineralized freeze-dried bone allograft (DFDBA) and the left side was filled with Stypro. In protocol C, the right-side defect was filled with Bio-Oss and the left side was filled with autogenous bone. The percentage of new bone formation was evaluated histomorphometrically after 8 weeks. Results: The mean bone formation was $68.19 \%$ for autogenous bone, $66.96 \%$ for MBCP Gel, 57.28\% for Bio-Oss, $50.19 \%$ for DFDBA, $18.79 \%$ for Stypro, and $10.61 \%$ for the empty control. Except for the MBCP Gel and autogenous bone groups $(\mathrm{P}=.6)$, the differences between the other groups were statistically significant $(\mathrm{P}<.05)$. Conclusion: The results of this study indicated that all the testing materials had different capacities to produce new bone in CSD of guinea pig calvaria. MBCP Gel showed promising results in producing new bone proportionate to the autogenous bone graft group. INT J ORAL MAXILLOFAC IMPLANTS 2013;28:1370-1376. doi: 10.11607/jomi.2906
\end{abstract}

Key words: autogenous bone graft, CSD, DFDBA, guinea pig, MBCP Gel, Stypro

\footnotetext{
${ }^{1}$ Assistant Professor, Department of Periodontics, School of Dentistry, Shiraz University of Medical Sciences, Shiraz, Fars, Iran.

${ }^{2}$ Assistant Professor, Department of Periodontics, School of Dentistry, Bushehr University of Medical Sciences, Bushehr, Iran.

${ }^{3}$ Assistant Professor, Department of Periodontics, School of Dentistry, Zahedan University of Medical Sciences, Zahedan, Iran

${ }^{4}$ Associate Professor, Department of Periodontics, School of Dentistry, Shiraz University of Medical Sciences, Shiraz, Fars, Iran

${ }^{5}$ Associate Professor, Department of Pathology, Medical School, Shiraz University of Medical Sciences, Shiraz, Fars, Iran

${ }^{6}$ Assistant Professor, Department of Periodontics, School of Dentistry, Shahid Beheshti, University of Medical Sciences, Tehran, Iran
}

Correspondence to: Dr Farin Kiany Yazdi, Periodontic Department, Dental School, Shiraz University of Medical Sciences, Ghasrodasht Street, Shiraz, Iran.

Fax: +987116270325 E-mail: farinkiany@yahoo.com

@2013 by Quintessence Publishing Co Inc.
C omplex surgical procedures are usually recommended for bone regeneration in areas where insufficient bone volume prevents the generation of new bone. ${ }^{1}$ Characteristics of an ideal graft material are osteogenesis, osteoinduction, and osteoconduction. Additionally, grafting materials should be resorbed gradually and replaced by newly formed bone. ${ }^{2}$

For some time, only autogenous bone graft fulfilled all of these requirements. However, the limited source of autografts in the oral cavity and the postsurgical complications associated with the use of extraoral grafts encouraged clinicians to consider other biomaterials for bone regeneration procedures. ${ }^{3}$

Therefore, many physicians have now turned to other grafting materials in order to avoid separate surgical procedures for obtaining graft material and to enhance the patient's comfort and convenience. Allografts or human grafts have been tested for their osteoconductive characteristics. These materials are transferred from a donor to a recipient, both of the same species but of dissimilar genetic composition. ${ }^{4,5}$ The demineralized freeze-dried bone allograft (DFDBA) is considered 
a source of collagen type I and bone morphogenic proteins which cause osteoinduction. ${ }^{4}$ However, because of the lack of inorganic mineralized components in these materials, they are not suitable as the scaffolding needed for bone regeneration and therefore are not osteoconductive. $^{4}$

Exfuse (Hans Biomed) is a novel DFDBA in putty form, to which deproteinized corticocancellous bone chips are added. It is claimed that it has the ability to stimulate mesenchymal cell proliferation in addition to conducting osseous tissue. Also, the addition of polymer excipient enhances the feasibility of implantation for this material. ${ }^{6}$

The other commonly used grafting material is xenograft, which is derived from donors of different species. After totally removing the organic protein component of these materials, the inorganic structure is used as a natural architecture matrix known to be rich in calcium. These materials are mostly osteoconductive. ${ }^{7}$

Bio-Oss (Geistlich) is a xenograft material obtained from bovine hydroxyapatite (HA). One of the advantages of this material is the similarity of its chemical composition to human HA, since the proportion of calcium and phosphate in this material is 1.67 , identical to that in human bone HA. ${ }^{1}$ The diameter of calcium crystals in the Bio-Oss mineral matrix is $100 \mu \mathrm{m}$, which is also similar to that of the human matrix. ${ }^{8}$ In addition, because of its surface topography, osteoblastic linkage and bone matrix formation appear on its superficial layer. ${ }^{9}$ It is now one of the most frequently used biomaterials in bone regeneration procedures.

The third generation of grafting materials is alloplast materials. These synthetic materials enjoy the following advantages: they have relatively low cost, they do not induce immunologic or infectious problems, and they have a higher resorption rate compared with $\mathrm{HA}$ materials. This last characteristic allows for bone formation simultaneously with material resorption. These materials are considered to be osteoconductive. ${ }^{2,10,11}$

MBCP Gel (Biomatlante) is a composite biomaterial obtained by the association of macroporous biphasic calcium phosphate in a polymeric carrier phase (hydroxyl propyl methyl cellulose, HPMC). This material consists of HA and beta-tricalcium phosphate ( $\beta$-TCP) with a weight ratio of $60 / 40$. It is suggested that this ratio causes an optimum balance in the more stable phase of $\mathrm{HA}$ and the more soluble TCP, leading to ideal solubility of the graft material in vivo and bone formation at a similar rate. ${ }^{12}$

Stypro (Curasan) is a biodegradable gelatin sponge of porcine origin with the ability to promote hemostasis. This material is used for immediate hemocoagulation. Since this process is the first step in tissue repair and healing, its application in well-maintained defects for inducing bone regeneration is appropriate. ${ }^{13}$
A critical-size defect (CSD) is a bony defect in an animal model for evaluation of bone healing. A CSD is the smallest diameter of intraosseous wound that would not heal spontaneously without bone grafting during the lifetime of the animal. ${ }^{4}$

The purpose of this study is to assess the healing capability of novel allograft and alloplast materials discussed above and to compare them with the gold standard grafting material (autogenous bone) and BioOss, one of the most common commercially available xenografts. The biomaterials were implanted in the calvaria of guinea pigs as a model for CSD evaluation of bone repair.

\section{MATERIALS AND METHODS}

Thirty six male guinea pigs 6 months of age, weighing on average about $500 \mathrm{~g} \pm 100 \mathrm{~g}$ were used in the study. The animals were randomly divided into three equal groups according to experimental protocol.

In protocol A, MBCP Gel was inserted in the rightside defect (group 1) and the left side remained empty (group 2, control group) and left to fill with a blood clot. In protocol B, Exfuse was placed in the right-side defect (group 3) and Stypro in the left side (group 4). In protocol $\mathrm{C}$, the right-side defect was filled with Bio-Oss (group 5) and autogenous bone was placed in the left side (group 6).

\section{Surgical Procedure}

The animals were anesthetized intramuscularly with a mixture of ketamine hydrochloride $(35 \mathrm{mg} / \mathrm{kg}$ ) and $2 \%$ xylazine hydrochloride $(2 \mathrm{mg} / \mathrm{kg}$ ). The frontoparietal skin of each animal was subjected to trichotomy and asepsis with $10 \%$ povidone iodine and the surgical area was isolated. A straight-shaped incision from the nasofrontal suture to the external occipital protuberance was made. Flaps were elevated by periosteal elevator to expose the parietal bone. Two fullthickness defects were created in the parietal bone using a trephine bur (8-mm external diameter) connected to a low-speed handpiece (gear ratio 72:1, maximum speed $500 \mathrm{rpm}$ ) under continuous and copious irrigation with $0.9 \%$ sterile saline to reduce possible thermal damage. The full-thickness craniotomies created in the parietal bone were posterior to the coronal suture and, while the least distance from the outer aspect of the defects to sagittal suture was $2 \mathrm{~mm}$, care was taken not to cross the midline. The round bone lid was removed with a chisel with light movement to fracture the remaining bone below the incision site. The dura mater was kept uninjured throughout the procedures. All the stages of the surgical procedures were performed under sterile conditions. 


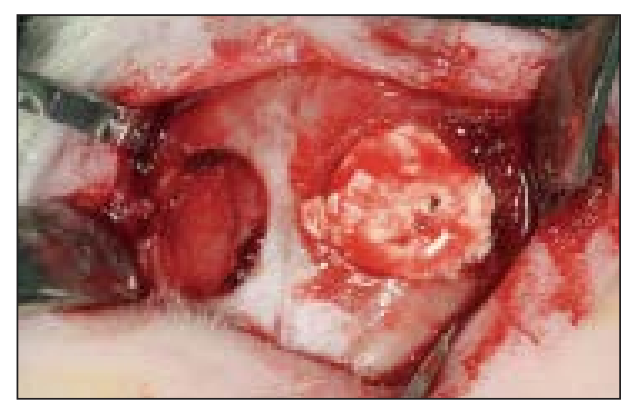

According to each protocol, the planned grafting material was positioned in the right- and left-side defects according to the manufacturers' guidelines (Fig 1). No isolating membrane was used over the materials. The soft tissues were then repositioned carefully and sutured layerly (with deep and superficial suturing) to achieve primary closure.

After suturing, oxytetracycline antibacterial skin spray was applied to the surgical wound. The animals received postoperative antibiotic penicillin-sodium ( $50 \mathrm{mg} / \mathrm{kg}$ per day) for 3 days by intramuscular injection. Each animal was coded with an individual marker representing its treatment protocol. Each coded animal was then caged separately and received water ad libitum as well as sufficient food.

After 8 weeks, the animals were sacrificed placing them in a closed jar with lethal doses of ether. The calvaria of the guinea pigs were then dissected.

\section{Histologic and Histomorphometric Analysis}

On average, two central sections of each specimen were used for the histologic evaluation, representing approximately $30 \mathrm{~mm}$ of the central aspect of the osteotomy defect. Each section was evaluated for new bone formation, grafting material remnants, and inflammatory responses by an experienced pathologist. Sections were viewed by light microscopy (BX 51, Olympus) with the objective lens set at $4 \times$ and $10 \times$. The digital image of each section with the magnification rate of $4 \times$ was captured by a camera (DP 25, Olympus), attached to the light microscope, saved in a computer, and analyzed for further histomorphometric analysis with Photoshop CS2 software (Middle Eastern version 9). Since all the borders of the defects could not be captured in one image, two images of each section were taken and stitched together with the software in order to create a composite image of the entire defect. Following the software guidelines, researchers saved total pixels of the defects for each section as well as the pixels of new bone formation delineated by the software. The percentage of new bone formation was calculated for each defect image section using the following formula:

\section{NB\% $=$ New bone pixels/Total defect pixels}

The mean value of new bone formation was achieved by calculating the mean bone formation of two sections per specimen. The values of new bone formation for each specimen were then used to calculate the means and standard deviations of the six groups under study.

\section{RESULTS}

\section{Histologic Evaluation}

According to the assessment of the pathologist, the new bone formation in the unfilled control group (group 2) was scarce and mainly restricted to areas close to the margins of the defects. The remaining areas were predominantly filled with fibrous connective tissue comprising fibroblasts and blood vessels. Excessive inflammatory cells were seen in the defect. The greatest amount of inflammation was seen in this group.

In groups 1 and 5 (grafted with MBCP Gel and BioOss, respectively), it was observed that grafting materials were distributed throughout the whole defect. Bone formation was developed throughout the defect on the trajectory of the grafted materials. Signs of resorption of grafting materials and formation of new osteoid in resorptive lacunae were observed. No significant inflammatory reaction was seen in these groups (Figs 2 and 3 ).

Histologic observation in group 3 (grafted with DFDBA) demonstrated grafting material resorption within 2 months. Osteoid formation was seen in both the periphery and center of the defects, but decreasing from margins to center. Similar to other groups, inflammatory reactions were minimal (Fig 4).

In group 4 (grafted with Stypro), bone formation was scarce in the center of the defect, and the fibrosis patterns were similar to those seen in group 2, although this group presented a lower inflammatory reaction.

Group 6 showed excellent bone formation. The new osteoid was distinguished from the remaining autogenous grafted bone by the presence of the osteocyte and lacunar spaces around these cells. 


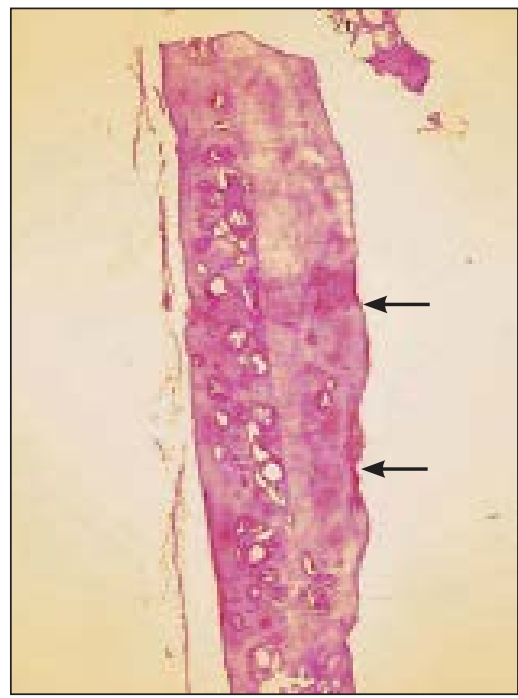

Fig 2 Histologic image of graft materia remnants and new bone formation (arrows) in a defect grafted by MBCP Gel in group 1. $(\times 4$ magnification, hematoxylineosin stain).

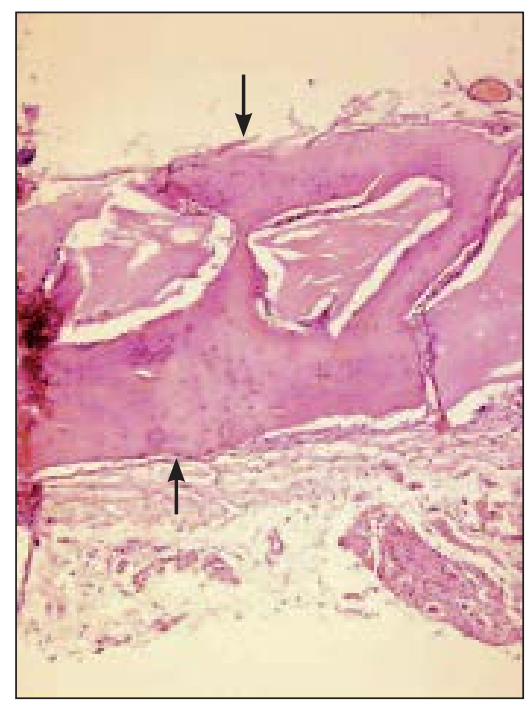

Fig 3 Satisfactory bone formation (arrows) in defects grafted with Bio-Oss in group 5. (×4 magnification, hematoxylineosin stain).

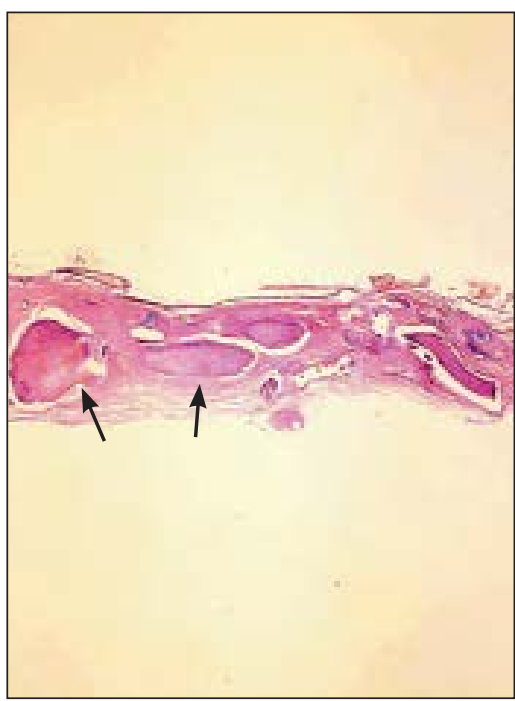

Fig 4 Histologic section showing bone formation (arrows) in the site grafted with Exfuse. ( $\times 4$ magnification, hematoxylineosin stain).

\section{Table 1 Mean Bone Formation (\%)}

\begin{tabular}{lccc} 
Group & Mean & $\mathbf{n}$ & SD \\
\hline 1 & 66.96 & 12 & 4.74 \\
\hline 2 & 10.61 & 12 & 2.14 \\
3 & 50.19 & 12 & 3.69 \\
\hline 4 & 18.79 & 12 & 3.03 \\
\hline 5 & 57.28 & 12 & 4.51 \\
\hline 6 & 68.19 & 12 & 3.75 \\
\hline
\end{tabular}

$\mathrm{SD}=$ standard deviation.

\section{Histomorphometric Analysis}

As shown in Table 1, group 6 has the highest mean percentage of new bone formation (68.19\%), followed by group 1 (MBCP Gel, 66.96\%), group 5 (Bio-Oss, 57.28\%), group 3 (Exfuse, 50.19\%), group 4 (Stypro, 18.79\%), and eventually group 2 (control, 10.61\%).

As shown in Tables 2 and 3, the intergroup analysis between dependent and independent groups, with the exception of groups 1 and 6, exhibited statistically significant differences between them $(P<.05)$.

\section{Statistical Analysis}

The means and standard deviations were obtained by SPSS (IBM) software. To compare new osteoid formation within each protocol of treatment (the dependent samples $A, B$, and $C$ ), the nonparametric Wilcoxon signed rank test was performed. The Mann-Whitney $U$ test was used to compare new bone formation in different groups in the three protocols defined above. The level of statistical significance was set at $5 \%(P \leq .05)$.
Table 2 Statistical Analysis Between

Dependent Pairs

\begin{tabular}{lcccccc} 
& & \multicolumn{4}{c}{$\begin{array}{c}95 \% \mathbf{C l} \text { of } \\
\text { Difference }\end{array}$} & \\
\cline { 3 - 5 } Group & Mean & SD & Lower & Upper & P Value \\
\hline $1-2$ & 56.64 & 5.39 & 52.91 & 59.77 & $<.002$ \\
$3-4$ & 31.39 & 4.71 & 28.39 & 34.39 & $<.002$ \\
\hline $5-6$ & 10.91 & 4.60 & 7.98 & 13.83 & $<.002$ \\
\hline
\end{tabular}

$\mathrm{SD}=$ standard deviation, $\mathrm{Cl}=$ confidence interval.

\section{DISCUSSION}

Bone is a commonly transplanted tissue in humans that is used to repair defects with various etiologic factors such as trauma, neoplasia, and infection. ${ }^{14}$ The use of several bone substitutes has been advocated for bone regeneration. Osteoprogenitor cells, osteoinductive growth factors, and osteoconductive matrices are three key elements that are necessary for generating and maintaining new bone tissue. These three characteristics should be included in biomaterials used for the stimulation of osseous regeneration. Grafting materials should also be able to be gradually resorbed and replaced by newly regenerated bone. ${ }^{1}$

Autogenous bone is usually the preferred graft material because it comprises all the previously mentioned characteristics. In addition, it is completely biocompatible, nontoxic, and nonimmunologic. It is also well accepted by the body and rapidly integrates into surrounding bone tissue. ${ }^{1}$ Thus, in comparison with 
Table 3 Statistical Analysis Between Independent Pairs

\begin{tabular}{|c|c|c|c|c|c|c|}
\hline Pair & Group & Mean & n & SD & SE Mean & $P$ value \\
\hline 1 & $\begin{array}{l}1 \\
3\end{array}$ & $\begin{array}{l}66.9617 \\
50.19\end{array}$ & $\begin{array}{l}12 \\
12\end{array}$ & $\begin{array}{l}4.74977 \\
3.69354\end{array}$ & $\begin{array}{l}1.37114 \\
1.06623\end{array}$ & $\begin{array}{l}<.001 \\
<.001\end{array}$ \\
\hline 2 & $\begin{array}{l}1 \\
4\end{array}$ & $\begin{array}{l}66.9617 \\
18.7967\end{array}$ & $\begin{array}{l}12 \\
12\end{array}$ & $\begin{array}{l}4.74977 \\
3.03587\end{array}$ & $\begin{array}{l}1.37114 \\
0.87638\end{array}$ & $\begin{array}{l}<.001 \\
<.001\end{array}$ \\
\hline 3 & $\begin{array}{l}1 \\
5\end{array}$ & $\begin{array}{l}66.9617 \\
57.2833\end{array}$ & $\begin{array}{l}12 \\
12\end{array}$ & $\begin{array}{l}4.74977 \\
4.51586\end{array}$ & $\begin{array}{l}1.37114 \\
1.30362\end{array}$ & $\begin{array}{l}<.001 \\
<.001\end{array}$ \\
\hline 4 & $\begin{array}{l}1 \\
6\end{array}$ & $\begin{array}{l}66.9617 \\
68.195\end{array}$ & $\begin{array}{l}12 \\
12\end{array}$ & $\begin{array}{l}4.74977 \\
3.75893\end{array}$ & $\begin{array}{l}1.37114 \\
1.08511\end{array}$ & $\begin{array}{l}<.001 \\
<.001\end{array}$ \\
\hline 5 & $\begin{array}{l}2 \\
3\end{array}$ & $\begin{array}{l}10.6133 \\
50.19\end{array}$ & $\begin{array}{l}12 \\
12\end{array}$ & $\begin{array}{l}2.14123 \\
3.69354\end{array}$ & $\begin{array}{l}0.61812 \\
1.06623\end{array}$ & $\begin{array}{l}<.001 \\
<.001\end{array}$ \\
\hline 6 & $\begin{array}{l}2 \\
4\end{array}$ & $\begin{array}{l}10.6133 \\
18.7967\end{array}$ & $\begin{array}{l}12 \\
12\end{array}$ & $\begin{array}{l}2.14123 \\
3.03587\end{array}$ & $\begin{array}{l}0.61812 \\
0.87638\end{array}$ & $\begin{array}{l}<.001 \\
<.001\end{array}$ \\
\hline 7 & $\begin{array}{l}2 \\
5\end{array}$ & $\begin{array}{l}10.6133 \\
57.2833\end{array}$ & $\begin{array}{l}12 \\
12\end{array}$ & $\begin{array}{l}2.14123 \\
4.51586\end{array}$ & $\begin{array}{l}0.61812 \\
1.30362\end{array}$ & $\begin{array}{l}<.001 \\
<.001\end{array}$ \\
\hline 8 & $\begin{array}{l}2 \\
6\end{array}$ & $\begin{array}{l}10.6133 \\
68.195\end{array}$ & $\begin{array}{l}12 \\
12\end{array}$ & $\begin{array}{l}2.14123 \\
3.75893\end{array}$ & $\begin{array}{l}0.61812 \\
1.08511\end{array}$ & $\begin{array}{l}<.001 \\
<.001\end{array}$ \\
\hline 9 & $\begin{array}{l}3 \\
5\end{array}$ & $\begin{array}{l}50.19 \\
57.2833\end{array}$ & $\begin{array}{l}12 \\
12\end{array}$ & $\begin{array}{l}3.69354 \\
4.51586\end{array}$ & $\begin{array}{l}1.06623 \\
1.30362\end{array}$ & $\begin{array}{l}<.001 \\
<.001\end{array}$ \\
\hline 10 & $\begin{array}{l}3 \\
6\end{array}$ & $\begin{array}{l}50.19 \\
68.195\end{array}$ & $\begin{array}{l}12 \\
12\end{array}$ & $\begin{array}{l}3.69354 \\
3.75893\end{array}$ & $\begin{array}{l}1.06623 \\
1.08511\end{array}$ & $\begin{array}{l}<.001 \\
<.001\end{array}$ \\
\hline 11 & $\begin{array}{l}4 \\
5\end{array}$ & $\begin{array}{l}18.7967 \\
57.2833\end{array}$ & $\begin{array}{l}12 \\
12\end{array}$ & $\begin{array}{l}3.03587 \\
4.51586\end{array}$ & $\begin{array}{l}0.87638 \\
1.30362\end{array}$ & $\begin{array}{l}<.001 \\
<.001\end{array}$ \\
\hline 12 & $\begin{array}{l}4 \\
6\end{array}$ & $\begin{array}{l}18.7967 \\
68.195\end{array}$ & $\begin{array}{l}12 \\
12\end{array}$ & $\begin{array}{l}3.03587 \\
3.75893\end{array}$ & $\begin{array}{l}0.87638 \\
1.08511\end{array}$ & $\begin{array}{l}<.001 \\
<.001\end{array}$ \\
\hline
\end{tabular}

$\mathrm{SD}=$ standard deviation, $\mathrm{SE}=$ standard error.

other grafting materials, autogenous bone is considered the gold standard. ${ }^{14}$ However, the limited quantity of available bone, the need for an additional surgical procedure, and postoperative morbidity at the donor site have restricted the use of autogenous bone grafting techniques. Therefore, clinicians are usually forced to use other biomaterials for bone regeneration. ${ }^{1}$

Gauthier et $\mathrm{al}^{15}$ used MBCP Gel in rabbit femurs, and found that bone colonization progresses from the periphery of the defect toward the center after 8 weeks. In the present study, bone formation in MBCP Gel group was also observed throughout the defect after 8 weeks.

Since MBCP Gel has an optimized balance between the more stable phase of the component $(\mathrm{HA})$ and the more soluble phase ( $\beta-\mathrm{TCP})$, it is possible to control the resorbability of the material and maintain its osteoconductivity at the same time. ${ }^{16}$

The histologic observation in this study confirmed the findings by Daculsi et al. ${ }^{17}$ In both studies, MBCP Gel leads to angiogenesis and osteogenesis on the surface as well as in the depth of the implanted area. ${ }^{17}$

To the authors' best knowledge there is no study that compares the healing pattern of $\mathrm{MBCP}$ Gel and autogenous bone. In the present study comparing the healing pattern of MBCP Gel and autogenous bone, no significant difference was found with regard to mean percentage of bone formation. This shows the excellent capability of MBCP Gel for new bone formation.

Exfuse putty is a mixture of demineralized bone matrix (DBM) and $4 \%$ sodium hyaluronate. The major reason for the addition of sodium hyaluronate is to improve the biocompatibility and clinical feasibility. ${ }^{18}$

Although DFDBA is one of the grafting materials routinely used in regenerative treatments, still there are some controversies regarding its osteoinductive capability. This material poses the risk of immunologic rejection, blood group incompatibility, and transmission of bacterial and viral infections and tumor cells and therefore requires special manufacturing considerations. ${ }^{1}$

In the present study, the mean percentage of new bone formation for DFDBA was $50.19 \%$, which is in agreement with Chesmel et $\mathrm{al}^{19}{ }^{19}$ Buser et $\mathrm{al}^{20}$ and Mokbel et al. ${ }^{4}$ In contrast to de Oliveira et al, ${ }^{21}$ whose research did not show good osteoinductive capability of DFDBA, and Becker et al, ${ }^{22}$ who showed limited bone repair by DFDBA, the findings of this study suggested good bone repair within the defects.

The results of the present study also revealed a higher mean bone formation using MBCP Gel in com- 
parison with that of DFDBA. This is in contrast with Fleckenstein et $\mathrm{al}^{14}$ who observed a higher mean bone formation in guinea pig CSDs that were filled with DFDBA comparing to those filled with HA-TCP macroporous disks.

As these studies show, there are different findings regarding DFDBA osteoinductive capability. According to Sampath and Reddi ${ }^{23}$ and Kenley et al, ${ }^{24}$ the amount of bone morphogenic proteins in demineralized matrix depends on donor and recipient sites. Also, during the production of DFDBA, certain processes can lead to the concentration of more osteoinductive factors in the matrix. These factors are known to be responsible for the diverse results achieved. ${ }^{1}$

Bio-Oss is viewed as a non-resorbable material because it needs several years ( 3 to 6 years) of implantation before showing some slow in vivo resorption. ${ }^{25}$ In the present study, Bio-Oss showed good osteoconductive characteristics in agreement with other reports. ${ }^{4,26}$ In contrast with Mokbel et $\mathrm{al}_{1}{ }^{4}$ in the present study, Bio-Oss showed significantly more bone formation than DFDBA. Moreover, comparing Bio-Oss with MBCP Gel, MBCP Gel showed better osteoconductive ability compared to Bio-Oss.

Given the importance of critical graft stabilization, it should be noted that micromotion can inhibit bone growth on the biomaterial surface, leading to fibrosis and the predominant growth of connective tissue at the healing site rather than osseous healing. ${ }^{27}$ In this study, great care was given to stabilize the Bio-Oss particles in the osteotomy site, but some washing-out of the graft material was inevitable. This partial loss of grafting material can partly account for the lower mean bone formation in the Bio-Oss group compared with MBCP Gel.

Therefore, in order to stabilize the material and to prevent dispersion of the particles when working with particulate graft materials such as Bio-Oss, it is better to use a membrane barrier to cover the osteotomy site. Since guided bone regeneration was not the purpose of the present study, the authors did not use membrane in this research. Thus, the loss of a certain amount of particulate materials was inevitable.

Stypro is a sterile, resorbable gelatin sponge with a hemostatic effect. This hemostatic effect is due to the physical properties of the material rather than the alteration of blood clotting mechanisms. ${ }^{13}$ Since angiogenesis is a prerequisite for tissue healing, the authors had predicted that using Stypro in well-maintained defects would increase bone formation. Although the results regarding Stypro showed significantly more bone formation in comparison to the unfilled control group, other grafting materials showed even better results. Perhaps lysis of Stypro after 14 days had a deleterious effect in this regard, mainly because hard tissue regeneration needs more time to occur.
None of the materials tested in this study elicited an adverse inflammatory reaction that could prevent the bone apposition process. This confirms that all grafted materials were biocompatible. As mentioned earlier, a CSD is a defect which has less than $10 \%$ bony regeneration during the lifetime of the animal. ${ }^{28}$ For more practical purposes, it has been recommended that if there is no complete osseous regeneration after 56 weeks ( 1 year), there will never be a complete bony regeneration and the defect can be considered as a CSD. ${ }^{29}$ Different animal models have been proposed for creating CSDs. Among these animals, rats and mice show a very high metabolic rate which leads to a high rate of new bone formation, unlike the metabolic and bone formation rate in human beings. ${ }^{29}$

Different sizes have been reported for CSDs in guinea pig calvaria. While Cestari et al ${ }^{30}$ reported a $9.5-\mathrm{mm}$ diameter CSD in guinea pigs, Taga et $\mathrm{al}^{31}$ considered a 9-mm defect as a CSD in this animal model. Gosain et $\mathrm{al}^{32}$ reported that linear measures might not provide an accurate evaluation of new bone formation within a CSD. Also, the concept of a CSD can be more accurately described using a three-dimensional assessment based on the cross-sectional area of deposited new bone. According to their three-dimensional study, a 5-mm defect is a CSD in guinea-pig calvaria. ${ }^{32}$

Due to the dimensional limitations of producing large-size defects in guinea pig calvaria, two 8-mm defects were used as CSDs. This diameter permits a sufficient distance between two defects. This could avoid the direct influence of the grafted materials on the healing process between two adjacent defects.

It is also worth mentioning that, so as not to overestimate or underestimate the bone regenerative capability of the grafting materials, all were compared with ungrafted defects (control group) and also with the gold standard (autogenous bone).

\section{CONCLUSIONS}

The results of this study indicate that all the testing materials (autogenous bone, MBCP Gel, Bio-Oss, DFDBA [Exfuse], and Stypro) show different capabilities in producing new bone in CSDs in guinea pigs without eliciting a significant inflammatory reaction.

It can also be suggested that the macroporous HA-TCP combination may elicit significant new bone formation. This is mainly due to the combination of the available pore size and rigid space-maintaining scaffold that HA-TCP provides.

This study also confirms that after 8 weeks, BCP particles, like the autogenous bone, can conserve their bioactivity and be conductive in extensive early bone substitution. 


\section{ACKNOWLEDGMENTS}

The authors thank the Vice-Chancellory of Shiraz University of Medical Science for supporting this research. The authors also thank Dr Tanide and the personnel of the Shiraz University Animal House. The authors would like to thank Dr Mehrdad Vosoughi for statistical analysis and Dr Ehya Amalesaleh for help with the English in the manuscript. This manuscript is based on a thesis by Dr Ehsan Mostaghni and Dr Somaye Ansari Moghadam. The authors reported no conflicts of interest related to this study.

\section{REFERENCES}

1. Tamimi FM, Torres J, Tresguerres I, Clemente C, Lopez-Cabarcos E, Blanco LJ. Bone augmentation in rabbit calvaria: Comparative study between Bio-Oss and a novel beta-TCP/DCPD granulate. J Clin Periodontol 2006;33:922-928.

2. Giannoudis PV, Dinopoulos H, Tsiridis E. Bone substitutes: An update. Injury 2005;36:s20-s27.

3. Block MS, Kent JN. Sinus augmentation for dental implants: The use of autogenous bone. J Oral Maxillofac Surg 1997;55:1281-1286.

4. Mokbel N, Bou Serhal C, Matni G, Naaman N. Healing patterns of critical size bony defects in rat following bone graft. Oral Maxillofac Surg 2008;12:73-78.

5. Reynolds MA, Bowers GM. Fate of demineralized freeze-dried bone allograft in human intrabony defects. J Periodontol 1996;67:150-157.

6. Human Tissue Engineering Corporation. Exfuse Catalog 2002. http://www.hansbiomed.com/English/2product/cat/dbm.pdf

7. Richardson CR, Mellonig JT, Brunsvold MA, McDonell HT, Cochran DL. Clinical evaluation of Bio-Oss: A bovine derived xenograft for the treatment of periodontal osseous defects in human. J Clin Periodontol 1999;26:421-428.

8. Rosen VB, Hobbs LW, Spector M. The ultrastructure of anorganic bovine bone and selected synthetic hydroxyapatites used as bone graft substitutes. Biomaterials 2002;23:921-928.

9. Acil Y, Terheyden H, Dunsche A, Fleiner B, Jepsen S. Three dimensional cultivation of human osteoblast-like cells on highly porous natural bone mineral. J Biomed Mater Res 2000;51:703-710.

10. Chow LC, Markovic M, Takagi S. A dual constant-composition titration system as an in vitro resorption model for comparing dissolution rates of calcium phosphate biomaterials. J Biomed Mater Res B Appl Biomater 2003;65:245-251.

11. Trisi P, Rao W, Rebaudi A, Fiore P. Histologic effect of pure-phase beta-tricalcium phosphate on bone regeneration in human artificial jawbone defects. Int J Periodontics Restorative Dent 2003;23:69-77.

12. Daculsi G, Rohanizadeh R, Weiss P, Bouler JM. Crystal polymer interaction with new injectable bone substitute; SEM and $\mathrm{Hr}$ TEM study. J Biomed Mater Res 2000;50:1-7.

13. Rohanizadeh R, Swain MV, Mason RS. Gelatin sponges as a scaffold for osteoblasts. J Mater Sci Mater Med 2008;19:1173-1182.

14. Fleckenstein KB, Cuenin MF, Peacock ME, et al. Effect of a hydroxyapatite tricalcuim phosphate alloplast on osseous repair in the rat calvarium. J Periodontol 2006;77:39-45.

15. Gauthier O, Goyenvalle E, Bouler JM, et al. Macroporous biphasic calcium phosphate ceramics versus injectable bone substitute: A comparative study 3 and 8 weeks after implantation in rabbit bone. J Mater Sci Mater Med 2001;12:385-390.
16. Gauthier O, Bouler JM, Weiss P, Bosco J, Daculsi G, Aguado E. Kinetic study of bone ingrowth and ceramic resorption associated with the implantation of different injectable calcium-phosphate bone substitutes. J Biomed Mater Res 1999;47:28-35.

17. Daculsi G, Laboux O, Malard O, Weiss P. Current state of the art of biphasic calcium phosphate bioceramics. J Mater Sci Mater Med 2003;14:195-200.

18. Takikawa S, Bauer TW, Kambic H, Togawa D. Comparative evaluation of the osteoinductivity of two formulations of human demineralized bone matrix. J Biomed Mater Res A 2003;65:37-42.

19. Chesmel KD, Branger J, Wertheim H, Scarborough N. Healing response to various forms of human demineralized bone matrix in athymic rat cranial defects. J Oral Maxillofac Surg 1998;56:857-863.

20. Buser D, Hoffmann B, Bernard JP, Lussi A, Mettler D, Schenk RK. Evaluation of filling materials in membrane-protected bone defects. A comparative histomorphometric study in the mandible of miniature pigs. Clin Oral Implants Res 1998;9:137-150.

21. de Oliveira RC, de Oliveira FH, Cestari TM, Taga R, Granjeiro JM. Morphometric evaluation of the repair of critical-size defects using demineralized bovine bone and autogenous bone grafts in rat calvaria. Clin Oral Implants Res 2008;19:749-754.

22. Becker W, Urist MR, Tucker LM, Becker BE, Ochsenbein C. Human demineralized freeze-dried bone: Inadequate induced bone formation in athymic mice. A preliminary study. J Periodontol 1995;66: 822-828.

23. Sampath TK, Reddi AH. Homology of bone-inductive proteins from human, monkey, bovine, and rat extracellular matrix. Proc Natl Acad Sci USA 1983;80:6591-6595.

24. Kenley RA, Yim k, Abrams J, et al. Biotechnology and bone graft substitutes. Pharm Res 1993;10:1393-1401.

25. Taylor JC, Cuff SE, Leger JP, Morra A, Anderson GL. In vitro osteoclast resorption of bone substitute biomaterials used for implant site augmentation: A pilot study. Int J Oral Maxillofac Implants 2002; 17:321-330.

26. Park JW, Jang JH, Bae SR, An CH, Suh JY. Bone formation with various bone graft substitutes in critical-sized rat calvarial defect. Clin Oral Implants Res 2009;20:372-378.

27. Hjorting-Hansen E, Worsaae N, Lemons JE. Histologic response after implantation of porous hydroxyl apatite ceramic in humans. Int J Oral Maxillofac Implants 1990;5:255-263.

28. Hollinger JO, Kleinschmidt JC. The critical size defect as an experimental model to test bone repair materials. J Craniofac Surg 1990; 1:60-68.

29. Schlegel KA, Lang FJ, Donath K, Kulow JT, Wiltfang J. The monocortical critical size bone defect as an alternative experimental model in testing bone substitute materials. Oral Surg Oral Med Oral Pathol Oral Radiol Endod 2006;10:7-13.

30. Cestari TM, Granjeiro JM, de Assis GF, Garlet GP, Taga R. Bone repair and augmentation using block of sintered bovine-derived anorganic bone graft in cranial bone defect model. Clin Oral Implants Res 2009;20:340-350.

31. Taga ML, Granjeiro JM, Cestari TM, Taga R. Healing of critical-size cranial defects in guinea pigs using a bovine bone-derived resorbable membrane. Int J Oral Maxillofac Implants 2008;23:427-436.

32. Gosain AK, Song L, Yu P, et al. Osteogenesis in cranial defects: Reassessment of the concept of critical size and the expression of TGF-beta isoforms. Plast Reconstr Surg 2000;106:360-371. 